\title{
Direitos Humanos e Política Social: instrumentos sóciojurídicos não punitivos e mecanismos democráticos
}

\author{
Human Rights and Social Policy: legal instruments socio not punitive \\ and democratic mechanisms
}

Cezar Bueno de Lima, Jucimeri Isolda Silveira*

Pontifícia Universidade Católica do Paraná, (PUCPR), Curitiba, PR, Brasil

\section{Resumo}

Este artigo aborda, a partir da teoria crítica, os fundamentos históricos dos Direitos Humanos e da Política Social, considerando os traços da formação social brasileira e latino-americana, e o contexto de crise do capital, de sociedades globalizadas e estruturalmente desiguais. A análise do modelo de proteção social meritocrático e do paradigma criminal punitivo, tem o objetivo de compreender o processo histórico de incidência de instrumentos e práticas reprodutoras da desigualdade. Como contra tendência, são consideradas novas possibilidades de solução de conflitos, pela aplicação da justiça restaurativa, e da participação social como diretriz, no processo de afirmação de políticas universais e intersetoriais para o enfrentamento de fenômenos sociais produzidos socialmente.

Palavras-chave: Direitos Humanos. Política Social. Justiça Restaurativa. Participação.

* CBL: Doutor em Ciências Sociais, e-mail: czarbueno@gmail.com JIS: Doutora em Serviço Social, e-mail: jucimeri.silveira@yahoo.com.br 


\section{Abstrat}

This article discusses, from the critical theory, the historical foundations of Human Rights and Social Policy, considering the characteristics of the Brazilian social formation and Latin America, and the capital's crisis context of globalized and structurally unequal societies. Analysis of the meritocratic social protection model and criminal punitive paradigm, aims to understand the historical process of incidence instruments and breeding inequality practices. As against trend, are considered new possibilities for conflict resolution, the application of restorative justice, and social participation as a guideline in the process of affirming universal and inter-sectoral policies for dealing with social phenomena produced socially.

Keywords: Human Rights. Social Policy. Restorative Justice. Participation.

\section{Introdução}

O aprofundamento da questão social, compreendida como expressão da desigualdade de classes, das respostas institucionais, das formas de organização e luta que ganham a esfera pública, na relação capital $x$ trabalho (CERQUEIRA FILHO, 1982), engendra condições para a afirmação de direitos humanos e a formulação de políticas públicas. Depreendese, a afirmação basilar de que direitos humanos e políticas públicas são fruto das relações de classes e camadas socais e destas com o Estado.

O modus operandi estatal na regulação da vida social, seja pela atuação na solução de conflitos ou na gestão das desigualdades via política social, expressa correlações de força e poder, dinamizadas por projetos de sociedade que ocupam o próprio Estado. Problematiza-se aqui, a compreensão dos limites impostos à efetivação dos direitos humanos no Brasil, tendo em vista a formação social, as marcas do processo de colonização na América Latina, e a incidência do neoliberalismo. De outra face, os desafios no processo democrático, notadamente pelo potencial emancipatório e o papel histórico da sociedade civil.

Parte-se da afirmação de que as transformações contemporâneas, num cenário de aprofundamento da desigualdade, em suas múltiplas 
manifestações, mediadas por disparidades nas relações de gênero, características étnico-raciais, orientação sexual, entre outras, oferecem limites na materialização de direitos. Neste contexto, a fragmentação e a redução dos fenômenos sociais, como pobreza e violência, dos direitos e das políticas públicas, traz como consequência, na esfera pública do Estado, hegemonizado por interesses conservadores e fragilmente tensionado por lutas emancipatórias e democráticas, a criminalização dos pobres, a mera gestão dos problemas em sociedade e a insuficiente solução de conflitos, que expressam para além da desobediência ao ordenamento jurídico, desigualdade estrutural.

O objetivo deste artigo é abordar, por meio de revisão bibliográfica, a relação entre teoria crítica dos Direitos Humanos e Políticas Públicas nos processos sociais que sinalizam os limites e as possibilidades históricas e sociais na construção da democracia. Neste sentido, o método de exposição do artigo aborda os Direitos Humanos no contexto da globalização e, aponta em seguida, a Política Social, estabelecendo uma relação entre controle meritocrático, processo democrático, quadro institucional de garantias fundamentais e fortalecimento organizações e sujeitos coletivos e apresenta, por último, a origem, características e viabilidade da aplicação da Justiça Restaurativa.

\section{Direitos Humanos como construção social em sociedades globalizadas e desiguais $^{1}$}

Desde as últimas décadas do século passado até o presente, as coalizões político-partidárias que ocuparam ou ocupam postos-chave no aparato de Estado estão, em alguma medida, subordinadas a plataformas políticas que suscitam a defesa e afirmação de Direitos Humanos.

1 Devido à polissemia de significados atrelados ao termo globalização optou-se, neste artigo, em utilizar a seguinte definição de, François Chesnais: 0 termo globalização apareceu por volta dos anos 80 (busness schools americanas) com 0 seguinte sentido: designar uma ação estratégica do grande grupo industrial e a necessidade deste adotar uma aproximação e uma conduta globais em direção aos mercados de demanda solvente, às fontes de abastecimento e aos movimentos dos rivais oligopólios. (CHESNAIS, François. Mundialização: 0 capital financeiro no comando. In: Outubro: Revista do Instituto de Estudos Socialistas, n.5, p.7-42, 2001, p.12). 
Ao mesmo tempo, solidarizam-se com medidas econômico-financeiras que diminuem o custo da intervenção do Estado, tornando-o racionalmente mais criminalizador do ponto de vista social e mais econômico do ponto de vista do dos interesses do mercado, no processo mundial de financeirização da economia e de modernização conservadora. A programática empresarial em torno dos ganhos de produtividade, racionalidade administrativa, meritocracia e gerencialismo, que servem de modelo operacional às grandes corporações econômico-financeiras e comerciais, são predominantemente, incorporadas nos planos da gestão estatal e disseminadas nos campos político e sociocultural. Essa tendência econômico-institucional incide diretamente na reprodução de discursos e práticas de intolerância claramente violadoras dos Direitos Humanos, no sentido da omissão quanto as possibilidades democráticas de sua reversão, especialmente dirigidas aos jovens pobres que vivem em periferias urbanas, com consequente moralização da questão social como problema individual.

Segundo Faria (2008), a combinação de fatores econômicos, tecnológicos, políticos e culturais promoveu a reestruturação global do capitalismo e imprimiu, no plano da relação entre Estado e aplicabilidade dos Direitos Humanos, poderosos obstáculos, uma vez que a promoção e execução de políticas públicas de defesa, proteção e promoção de direitos têm sido, no período, objeto de crítica e confronto de projetos políticos, favorecendo, dada a hegemonização dos interesses do capital, a restrição social do papel do Estado. A globalização econômico-financeira que constitui, por assim dizer, o pano de fundo explicativo para a progressiva distância entre discurso e efetividade dos direitos humanos, pode ser caracterizada:

[Pelo] desenvolvimento de bens e serviços de alto valor agregado em termos de conhecimento intelectual, da expansão dos processos de informatização dos sistemas de gestão e produção, da desregulamentação dos mercados financeiros, e internacionalização do sistema bancário, da transnacionalização dos capitais industriais e comerciais, de substituição da hierarquia pela ideia de rede como forma organizacional, da movimentação cada vez mais livre de mercadorias, serviços, tecnologia e informações, da intensificação das relações sociais e do 
aumento da abrangência geográfica das interações localmente relevantes (Faria, 2008, p.3)

Do ponto de vista político e institucional, prossegue o autor, as nações e governos assistem:

[A] progressiva internacionalização das decisões econômicas e a expansão de uma trama mundial de instituições estatais e privadas com autoridade pública; a subsequente dificuldade do sistema-político legislativo convencional de estabelecer regras do jogo estáveis e coerentes e o esgotamento da ideia de hierarquia como princípio ordenador da vida social [dificuldade crescente de demarcar o público do privado e de definir o território como fundamento e objeto do Estado]; rompimento da aliança histórica entre Estado nacional, sistema econômico e democracia representativa. (Faria, 2008, p.4-5)

Na mesma direção argumenta Carballido (2014), aspectos relacionados à concentração da riqueza, a assimetria de poder, a perda de direitos sociais, o aumento do desemprego, a expansão do trabalho informal, a exclusão social e a violência urbana tendem aprofundar a crise de legitimidade dos sistemas políticos democráticos nos âmbitos interno e externo.

Neste cenário de erosão dos direitos coletivos, os movimentos sociais assumem papel relevante desde que mostrem-se capazes de reconhecer o potencial político emancipador dos direitos humanos, pela participação social e ampliação do próprio Estado, repolitizando sua práxis. Para isso, de acordo com Carballido, os Direitos Humanos devem ser lidos e interpretados como um campo em disputa que abriga distintos paradigmas. Ao referir-se à teoria crítica, o autor argumenta que os Direitos Humanos representam uma "aposta teórica e política para tornar efetivo o potencial emancipador que subjaz a narrativa dos direitos humanos como produto histórico das lutas dos povos em busca de sua libertação" (2014, p.41-42).

Quanto ao posicionamento teórico-crítico de abordagem dos Direitos Humanos, a opção pelo diálogo aberto, cruzamento de paradigmas e horizontes teóricos, rejeita, desde logo, modelos institucionais ou normativos tradicionais de análise e interpretação dos 
Direitos Humanos, por entender que a matriz ocidental que lhe serve de base apresenta limites conceituais e culturais em relação ao contexto latino-americano. Dentre os desafios postos ao pensamento crítico na América Latina inclui-se o que deve identificar as pegadas coloniais contidas nos planos normativos e culturais dos direitos humanos evitando-se, assim, a mera recepção acrítica de "modelos intelectuais ocidentais, que dispensa o processo de recepção criativa, [produção de discurso próprio]". (Carballido, 2014, p.46).

Segundo o autor, a teoria crítica assume a complexidade da vida social e busca compreender, intervir, transformar, orientar escolhas, na direção emancipatória. Para além do esforço em estabelecer relações entre conceitos, as teorias produzem consequências práticas nos distintos âmbitos da ação. Este é o caso, por exemplo, das concepções reducionistas (legalistas) dos direitos humanos que servem à consagração dos sistemas normativos geridos pelo Estado, sem o acompanhamento de sua efetiva proteção (mecanismos de garantia). A efetivação dos direitos humanos implica, do ponto de vista da teoria crítica, a combinação "de um processo bastante complexo no qual se intervém aspectos normativos, políticos, ideológicos, sociais, culturais e econômicos". (Carballido, 2014, p.48). A efetivação de tais direitos, que não se esgotam nos processos de judicialização internacional e nacional, supõe desconstruir a cultura de insensibilidade coletiva reinante.

A versão liberal dos Direitos Humanos no mundo ocidental, sem dúvida a mais difundida e consolidada, atribui, segundo Carballido (2014), grande valor normativo aos Direitos Humanos e insiste em concebê-los a partir de uma "visão estática e legalista". Segundo o autor, tais direitos representam, no plano histórico-empírico, o "produto cultural desenvolvido no marco legitimador da modernidade ocidental capitalista", amparados pelas teorias jusnaturalistas e juspositivistas. Na medida em que os Direitos Humanos estão submetidos à hegemonia do discurso liberal, muitas práticas e lógicas não são propagadas oficialmente como violadoras de direitos.

Para o autor, o pensamento crítico confronta significações, discursos, instituições e personificações que produzem "estrutura de 
assimetria e desigualdade" e, ao fazê-lo, contribui para identificar e evidenciar "pressupostos nem sempre explícitos na doutrina hegemônica dos direitos humanos que afetam seu potencial emancipador nos processos de luta pela dignidade humana". O questionamento dirigido aos "saberes desenvolvidos pela doutrina liberal tradicional e hegemônica", caracterizados pela abstração, idealismo e legitimação de práticas imperialistas, abre caminho para a emergência de formas emancipadoras dos direitos. A elaboração de reflexões contextualizadas admite que não há norma, instituição e teoria perfeita porque "todas se estabelecem a partir de um determinado lugar de enunciação e sobre temas epistêmicos privilegiados". Neste sentido, a exigência de esforços que conduzam à autovigilância epistemológica representa um meio de se precaver e minimizar o risco de construção de "novas lógicas de vitimização [de] naturalização [e] normalização das construções humanas", (Carballido, 2014, p.45).

Quando se admite que os Direitos Humanos são o produto cultural submetido a processos históricos, a construções abertas e sujeitas a mudanças constantes e que, do ponto de vista das relações de força, nem o Estado ou as demais instituições que representam o poder não concedem direito, resta-nos enfatizar que capacidade de impactar e gestar realidades no âmbito político e jurídico depende de ideais postulados e intervenções no processo de construção da realidade social. A produção e difusão de diferentes narrativas em torno dos direitos humanos não estão imunes a interesses, pois dependem dos atores "que querem e necessitam mudar a história". Em especial, os grupos sociais empobrecidos e discriminados põem-se em condições de questionar e desnaturalizar as relações de poder, incluindo as que buscam promover e naturalizar a inevitabilidade do castigo e do encarceramento centralizado na figura do Estado. (Carballido, 2014, p.48-50).

Em países como o Brasil, principalmente, quando se observa a imposição do processo de colonização, dependência econômica, política e cultural do país, diante de algumas nações europeias e os EUA, torna-se imperativo contextualizar tanto a análise quanto a recepção dos discursos e práticas dos Direitos Humanos e identificar, para 
além da denúncia dirigida à suposta falta de observância, proteção e efetividade da aplicação dos mesmos à realidade brasileira, traços de incompatibilidade sociocultural e ideológica, oriundos da pretensão universal dos direitos humanos junto a nações submetidas a processos de dominação econômica, política e sociocultural. Neste caso, é importante ter em mente a genealogia econômica, política e sociocultural de ascensão da burguesia europeia a qual, sem pedir permissão e consentimento aos povos colonizados, inaugurou e conferiu força vinculante aos direitos do homem para além de suas fronteiras físicas e culturais. Tais marcas históricas aprofundaram a desigualdade em suas diversas expressões, influenciaram a estruturação de políticas públicas residuais e reprodutoras das relações de poder em sociedade, e ao mesmo tempo constituem o desafio no processo de consolidação dos direitos humanos e fortalecimento de mecanismos democráticos.

\section{Política Social: entre o controle meritocrático e o processo democrático}

Na era da sociabilidade moldada pelo capital os direitos e as políticas públicas possuem uma natureza contraditória, já que são engendrados na base de uma sociedade de classes produtora de relações desiguais. De outra face, materializam conquistas parciais no processo de reprodução social da vida, e de fortalecimento de uma cultura política emancipatória pela atuação da sociedade civil. Os Direitos Humanos são dotados de potencial democrático, por serem forjados nas lutas sociais, pela prática dos sujeitos sociais, na explicitação de carecimentos e desigualdades. Deste modo, ressalta-se a importância da qualificação legal-institucional de garantias fundamentais, o que inclui a produção de legislações e a institucionalidade de políticas públicas, em resposta às necessidades humanas, e do fortalecimento organizações e sujeitos coletivos, especialmente com grau maior de conscientização, no processo de democracia formal, indispensável, embora insuficiente. (Heller, 1982) 
O processo histórico de construção dos direitos expressa, no caso brasileiro, garantias tardias e inconsistentes, e uma cultura política assolapada pelos efeitos dos ciclos de autoritarismo. Do mesmo modo, as políticas sociais brasileiras carregam a marca da ineficiência e da ineficácia, com sobreposição de competências e processos de descontinuidades. Retratam, sobretudo, a adoção sistemática de mecanismos que associam disciplina, repressão e controle, o que reproduz a própria desigualdade.

Num contexto de produção de um Estado que expressa uma dada formação social, a partir da luta de classes social (Poulantzas, 2000), a política social é dinamizada por relações de poder que tendem à refuncionalizar as lógicas dominantes. Neste sentido, o Estado produz mecanismos progressivamente sofisticados para interferir no social, nas relações, fragmentando, individualizando e patologizando as demandas sociais.

A legitimidade de um projeto político no âmbito do Estado está assentada na produção de consensos que perpassam projetos coletivos diversos e que, portanto, vão além do emprego da força policial militar, tendo em vista a garantia da relativa estabilidade social. É neste processo que a política social torna-se funcional, sem com isso suprimir o espaço da contradição e da saturação das contradições da própria realidade social, ao sistema de produção da desigualdade e reprodução social ampliada.

A estruturação de um padrão de proteção social particularizado no Brasil a partir da década de 1930, delineia um Estado regulador da vida social para a reprodução da força de trabalho, por meio de um conjunto de instituições voltadas à administração de conflitos e da desigualdade social, no contexto de aprofundamento da questão social. Tal processualidade permitiu ao Estado atuar sobre demandas imediatas, considerando as pressões e interesses predominantes, conformando, assim, a particularidade de um sistema que combina meritocracia com corporativismo (Draibe, 1982). O padrão de proteção social brasileiro erguido na era dos monopólios caracteriza-se pela fragmentação, seletividade, meritocracia e focalismo em resposta às 
múltiplas expressões da questão social, compreendida como expressão da desigualdade.

A lógica da distinção social, pela agregação de poder obtida por vocação, talento e oportunidades, orientada pela lógica de base meritocrática, está sustentada por uma ideologia que localiza os indivíduos em suas posições sociais e econômicas pela capacidade comprovada socialmente, conformando um "darwinismo" social. Tal fundamento meritocrático influencia, até os tempos atuais, a definição de medidas institucionais para solução de conflitos em sociedade e de moralização do acesso da população aos serviços públicos (Silveira, 2013).

A Constituição de 1988 representa um marco doutrinário e organizativo pela afirmação da participação na descentralização de políticas públicas e construção da cidadania. Inaugura-se um novo período no processo democrático, inclusive, diante da crise orgânica instalada que expressava, sobretudo, diante da centralização e insuficiência no alcance social, o que desencadeou uma reforma administrativa para reorganizar as estruturas e instancias nas três esferas de governo.

Abordagens de matriz crítica, especialmente orientadas pela teoria social marxista, situam a participação social no contexto da afirmação e luta dos movimentos sociais, voltados à transformação das condições objetivas de vida, "de carências econômicas e/ou de opressões sociopolíticas e cultural" (Gohn, 2011, p. 27). O contrapondo às perspectivas conservadoras ressaltam a centralidade do processo emancipatório pelas classes e camadas sociais subalternizadas, o que ressalta o protagonismo dos sujeitos coletivos e de projetos políticos orientadores das práxis dos atores sociais inscritos em espaços sociais participativos, institucionalizados ou não.

O novo pacto federativo e a construção dos processos de realocação de funções e recursos, num sistema cooperativo com partilha de poder, preconizam o reconhecimento das desigualdades e assimetrias econômicas, políticas e culturais das regiões/localidades; os diferentes graus de participação das forças sociopolíticas; e a consolidação de uma cultura política e administrativa voltada à consolidação dos direitos humanos. 
As políticas públicas de proteção social são orientadas por princípios e diretrizes que demandam o necessário fortalecimento de mecanismos e processos democráticos, construídos a partir de pactos entre os entes federados e materializados nas regulamentações que qualificam a política social na esfera pública estatal, impulsionadas por uma direção política, que enfrentem os constrangimentos da descentralização e da formação social brasileira.

Os formatos de proteção social predominantes em diferentes contextos sócio históricos têm configurado a contradição entre a afirmação do direito de cidadania e os constrangimentos da atualidade os quais convertem-se em desafios para a gestão das políticas e construção das municipalidades. Em especial, quando percebe-se a baixa capacidade administrativa e a insuficiência na cooperação federativa na garantia de provisões que materializam direitos, acrescidas das tensões entre o patrimonialismo local pautado pelas relações de mando e favor, e organizações da sociedade civil com potencial emancipatória.

A análise do caso brasileiro permite a afirmação de que a descentralização não assume apenas o sentido de reordenamento técnico, fiscal ou administrativo, mas, como afirma Nogueira (1997), de uma descentralização de natureza política, considerando a diretriz da participação da sociedade. A descentralização incide profundamente sobre toda a estrutura do Estado, modificando-a e contribuindo para garantir a implementação de mecanismos de caráter democrático no seu ordenamento. De outra face, importante destacar, a descentralização pode ser pautada pelo complexo ideológico de gestão do mercado e do trabalho, sob a perspectiva do desenvolvimento, sendo concebida como um mecanismo que compõe o processo de ajuste estrutural, diante da globalização.

A política social possui o potencial democratizante, desde que dinamizada por competências democráticas de gestão, atendendo às diretivas republicanas; tensionada por forças sociais emancipatórias /democráticas e por práticas sociais e profissionais balizadas por princípios ético-políticos, associados a projetos societários que 
centralizam os Direitos Humanos como travessia indispensável para a construção de patamares superiores de sociabilidade.

Na contramão de modelos e processos de gestão gerencialistas, a gestão democrático-popular, dentre outros aspectos, procura valorizar o saber popular e rejeitar o clientelismo e outras formas de controle pelo Estado; estabelece canais e mecanismos de participação social na esfera pública do Estado, com fortalecimento do processo democrático. As possibilidades de implementação de instrumentos e dispositivos democráticos no Estado são possíveis e necessárias no enfrentamento e solução de fenômenos sociais complexos. Neste contexto, insere-se a Justiça Restaurativa.

\section{A potência da justiça restaurativa no processo de fortalecimento da participação social}

A expressão justiça restaurativa foi originariamente utilizada em 1977 para redefinir o conceito usual de crime como um tipo de violação que vincula as figuras do agressor, da vítima e da comunidade. Segundo Jaccoud (2005), o modelo de organização das sociedades comunais, sem Estado/coletividades nativas, foi caracterizado pela existência de práticas de regulamento social centradas na manutenção da coesão do grupo configurando-se, portanto, como práticas precursoras da justiça restaurativa. As transformações socioeconômicas, políticas e culturais das modernas sociedades ocidentais provocaram, em relação ao modelo de organização das sociedades comunais, a erosão dos interesses coletivos em prol dos interesses individuais. A emergência das modernas sociedades ocidentais caracterizadas pela centralização do poder, sob a forma de monarquias de direito divino e Estados democráticos centralizados, irá reduzir consideravelmente [as] formas de justiça negociada. No campo estatal, as opções político-jurídicas de solução dos conflitos como ocorreu, por exemplo, no caso da relação ofensa/punição, permitiram o poder (justiça) converter a vítima em mera coadjuvante da intervenção estatal. (p.164-165). 
Nas últimas décadas, o ressurgimento da justiça restaurativa está associado a uma complexa conjuntura marcada por transformações estruturais, ocorridas dentro e fora do campo penal, protagonizadas por movimentos de contestação das instituições repressivas (Escola de Chicago), a redescoberta da vítima (segunda guerra mundial) e a exaltação da comunidade. Outros fatores relacionados à desagregação do modelo estatal de bem estar-social, à crescente diferenciação e maior complexidade das relações sociais, ao simbolismo jurídico, ao maior protagonismo da sociedade civil, têm remodelado profundamente as relações entre os cidadãos e o estado". (Jaccoud, 2005, p.165-166).

Reflexões em torno da irracionalidade da ideia de punição, do alto custo econômico de funcionamento do sistema criminal retributivo, da expansão da violência urbana e inflação carcerária em diversos países, têm desafiado governos, instituições acadêmicas e movimentos em defesa dos direitos humanos a buscar, nos marcos da democracia representativa e participativa, alternativas político-institucionais como forma de reorientar o atendimento das necessidades individuais e coletivas e de responsabilizar as partes em conflito, sem excluir a figura da vítima, nem etiquetar a pessoa do ofensor.

Diante dos argumentos apontados, a Organização das Nações Unidas (ONU/2002) foi levada a instituir normas para encorajar os países membros a adotar princípios e métodos de justiça restaurativa como meio de reparar o dano causado à vítima, sem estigmatizar a figura do agressor. Entendimentos políticos e acadêmicos respaldados pela ONU procuram mostrar que as respostas sócio jurídicas voltadas à reparação, restituição, serviço comunitário, acordo restaurativo, círculos decisórios, entre outras, podem oferecer respostas mais adequadas aos conflitos. De modo mais específico, a resolução da ONU em questão define programa de justiça restaurativa como aquele que "utiliza processos restaurativos e procura alcançar resultados restaurativos". Já, ao reportar-se ao o processo restaurativo, a entidade estipula que este supõe as presenças: 
[Da] vitima, do agressor e, quando for o caso, [de] qualquer pessoa ou membro da comunidade afetada pelo delito, participem conjuntamente de forma ativa na resolução de questões derivadas do delito, em geral com a ajuda de um facilitador. [A mesma resolução cita, como exemplos de processos restaurativos, os procedimentos de mediação, conciliação, celebração de conversações e reuniões para decidir as sentenças]. (ONU, 2002).

Como se vê, o modelo de Justiça Restaurativa prevê o empoderamento das partes envolvidas no conflito as quais devem, de modo espontâneo, levar e participar das soluções dos conflitos, estabelecer procedimentos informais em espaços comunitários e contar com a presença de mediadores/facilitadores. O acordo restaurativo, ao contrário da forma tradicional de intervenção penal que conceitua o crime "como fato bruto [e] a reação social [focada na] pessoa do delinquente", utiliza técnicas de mediação, conciliação, transação, etc., cujo interesse recai sobre "as consequências do crime e as relações sociais afetadas pela conduta" (Prudente, Sabadell, 2008, p.52-53).

Outra consideração importante refere-se ao fato de as práticas da justiça restaurativas estarem diretamente associadas à construção e efetivação de políticas públicas. O envolvimento comunitário, condição para a viabilização das práticas restaurativas, só pode lograr êxito se houver "intervenção efetiva de uma rede de atendimento [políticas públicas] que dê amparo a uma gama de necessidades que se expressa em termos de serviços públicos sociais". Segundo o autor, a existência de muitos conflitos é a expressão das desigualdades sociais, ou seja, de necessidades não atendidas de alguma das partes. Os modelos restaurativos de solução de conflitos não se fecham "às diferenças, ao dinamismo da vida, às mudanças e às tensões envolvidas em toda mudança [incluindo] as oposições e os conflitos de interpretações". Repudiam a violência e as desigualdades sociais, mas não almejam "a busca de uma "paz homogeneizadora fundada na obediência e sujeição". (Mello, 2005, p.67).

Diante do exposto, o princípio do contrato e da vontade única universal que constroem as noções ordem e consenso, acompanhado da imposição de um direito exterior que tece soluções lógico-abstratas aos indivíduos de cima pra baixo, dá lugar a seres, vozes e ações que 
"vem de baixo, [munidos de] pulsões, paixões, ressentimentos, sensações, sentimentos que ditam as interpretações do mundo e [os] levam a agir e a interagir". Logo, os atores, antes de serem submetidos a sistemas formais de justiça e instituições educacionais que pouco os valorizam, são estimulados a interpretar, avaliar, julgar e estabelecer regras de conduta. Dentre os desafios da justiça restaurativa, concebida como um modelo teórico-valorativo de solução de conflitos que estrutura com base descentralização do poder, democracia participativa e saberes plurais, há que se superar a cultura do medo.

A capacidade de mobilização e ação política da sociedade civil organizada como os movimentos sociais, associações de moradores, ONG's e pastorais tende, no plano no plano da realidade empírica, promover formas de discussão e de atuação democrática, participativa e, em consequência, abrir caminho à institucionalização de práticas sociais de resistência às pretensões expansionistas do Estado punitivo, repressor e encarcerador.

A justiça restaurativa propõe, em oposição ao direito penal convencional que considera o "crime uma conduta típica, ilícita e culpável que atenta contra bens interesses penalmente tutelados", soluções que, segundo Prudente e Sabadell (2008 p.51), levem em conta o "compromisso de restaurar o mal causado às vítimas, famílias e comunidades". Sobressai, na relação indivíduo, Estado e sociedade, sem menosprezo das conquistas sociais expressas no rol de garantias e proteção dos Direitos Humanos, o empoderamento da comunidade na busca de soluções dos conflitos que a dizem respeito. Refuta soluções verticais "na definição do que é justo" e nega a cisão kantiana interioridade versus exterioridade. Por entender que o foco está mais na relação que na ação estatal, a vítima deixa de figurar como mero objeto de privação, ressentimento e desejo de vingança. A figura do agressor, comumente encarada como alvo da vingança, "de ações e o objeto de represálias", é elevada à condição de ator na composição dos conflitos. A quebra dos automatismos que caracteriza a moral binária fundada na relação vítima/comoção social x agressor/ódio e banimento, abre espaço à microfísica do poder onde as partes serão confrontadas a apresentar 
“perspectivas outras de avaliação que não as suas e, em consequência, "de reavaliar suas próprias condutas, de reavaliar a si mesmos". (Melo, 2005, p. 61-62).

É oportuno ressaltar que as opções acadêmico-políticas pela descentralização do poder institucional e o empoderamento da comunidade local não significa, em absoluto, aderir a concepções políticas ou a plataformas governamentais de retração de direitos e de terceirização das funções sociais do Estado. Tampouco, é o caso de considerar as críticas dirigidas ao modelo centralizador, repressor e encarcerador da justiça criminal convencional como uma crítica que exime o Estado de suas atribuições de encampar a defesa e promoção do trabalho digno, do direito efetivo à moradia, à educação, à saúde, ao acesso à justiça, etc. Enfim, conclui De Vitto (2005, p.46), que a justiça restaurava busca definir um "processo de construção e afirmação história dos direitos humanos". O reconhecimento do protagonismo da vítima e da comunidade local requer mudanças das formas de organização do poder e maior participação e controle social das instituições do Estado. As possibilidades de concretização do protagonismo político da comunidade local estão diretamente ligadas à expansão da cultura de participação democrática no âmbito de funcionamento das instituições estatais.

\section{Considerações Finais}

Nas sociedades contemporâneas, as transformações engendradoras de desigualdade sociais e restrição de direitos impõem, no campo das políticas criminais, da elaboração e execução das políticas públicas obstáculos incompatíveis à realização de projetos de vida emancipatórios almejados por jovens e adultos em situação de pobreza e vulnerabilidade social.

A reflexão teórica atenta e totalizadora da realidade social e das dinâmicas institucionais, permitem reconhecer que o distanciamento entre os propósitos oficiais de controle criminal e inclusão social e as aspirações de jovens e adultos, em especial, entre aqueles que se encontram em situação de vulnerabilidade social resulta, ao menos em 
parte, da pouca permeabilidade das políticas públicas sociais e de controle político-criminal em oferecer mecanismos e espaços de participação política que permitam, tanto aos primeiros quanto aos agressores, seus familiares e comunidade de referência, discutir, propor e deliberar sobre o conteúdo das respostas bem como as formas de executá-las, condizentes com a defesa e promoção dos Direitos Humanos.

A opção por modelos sócio jurídicos mais democráticos e descentralizadores na solução dos conflitos, como é o caso da justiça restaurativa, tende propiciar maior êxito de reinserção dos infratores quando comparados com ao modelo penal vigente, dirigido aos jovens e adultos. Ainda que se perceba a fragilidade das respostas intersetoriais das políticas públicas, as mesmas possuem o potencial transformador da realidade social vivida pela maioria da população inserida em territórios desiguais. Do mesmo modo, a justiça restaurativa representa uma perspectiva de posicionar a centralidade dos sujeitos de direitos e da própria sociedade civil em seu papel de ampliar o Estado. Processo que pode ser adensado e direcionado por práxis críticas que possam compor o processo de aplicação das novas formas de solução pacifica de conflitos, na perspectiva de sua desjudicialização, bem como alargar direitos pela atuação política de sujeitos coletivos.

\section{Referências}

CARBALLIDO, M. E. G. Repensando los Derechos Humanos desde las luchas. Revista de Direitos Fundamentais e Democracia, Curitiba, v. 15, n. 15, p. 41-52, jan/ jun, 2014.

CERQUEIRA FILHO, G. A questão social no Brasil: crítica do discurso político. Civilização Brasileira, Rio de Janeiro, 1982.

CHESNAIS, F. Mundialização: o capital financeiro no comando. In: outubro: Revista do Instituto de Estudos Socialistas, n.5, p.7-42, 2001. 
DE VITTO, R. C. P. Justiça Criminal, Justiça Restaurativa e Direitos Humanos. In. Slakmon, C, De Vitto e Renato Sócrates Gomes Pinto (Orgs). Justiça Restaurativa. Brasília/DF: Ministério da Justiça e Programa das Nações Unidas para o Desenvolvimento/PNUD, 2005.

DRAIBE, S. As políticas sociais brasileiras: diagnóstico e perspectivas. In: Para a década de 90: prioridades e perspectivas de políticas públicas. IPEA/IPLAN, Brasília, 1989.

FARIA, J. E. Direito e conjuntura. São Paulo: Saraiva 2008.

GOHN, M. da G. Conselhos gestores e participação sociopolítica. 4ª ed. São Paulo: Cortez, 2011.

HELLER. A. Para mudar a vida. Felicidade, liberdade e democracia. São Paulo: Brasiliense, 1982.

JACCOUD, M. Princípios, Tendências e Procedimentos que Cercam a Justiça Restaurativa. In. Slakmon, C, De Vitto e Renato Sócrates Gomes Pinto (Orgs). Justiça Restaurativa. Brasília/DF: Ministério da Justiça e Programa das Nações Unidas para o Desenvolvimento/PNUD, 2005.

MELO, E. R. Justiça restaurativa e seus desafios histórico-culturais: um ensaio crítico sobre os fundamentos ético-filosóficos da justiça restaurativa em contraposição à justiça retributiva. In. Slakmon, C, De Vitto e Renato Sócrates Gomes PINTO (Orgs). Justiça Restaurativa. Brasília/DF: Ministério da Justiça e Programa das Nações Unidas para o Desenvolvimento/PNUD, 2005.

POULANTZAS, N. O Estado, o poder, o socialismo. 4ª Ed. SP: Paz e Terra, 2000.

PRUDENTE, N. M.; SABADELL, A. L. Mudanças de paradigmas: justiça restaurativa. Maringá/PR. Revista Jurídica Cesumar, v. 8, n. 1, p. 49-62, jan./jun. 2008.

Resolução 2002/12 do Conselho Social e Econômico da ONU. Disponível em < http://file.fde.sp.gov.br/portalfde/arquivo/mediacao/articulacao.pdf $>$. Acesso em 20 de fevereiro, de 2015.

NOGUEIRA, M. A. Dimensão Política da Descentralização Participativa. Revista São Paulo em Perspectiva. VII, no 3 Fundação SEADE, 1997. 
SILVEIRA, J.I. Profissionalidade do Serviço Social: estatuto sócio jurídico e legitimidade construída no "modelo" de competências. 2013. 210 f. Tese (Doutorado em Serviço Social). Pontifícia Universidade Católica de São Paulo, São Paulo. 2013.

DA SILVA, E. G.; SALIBA, M. G. Justiça Restaurativa, sistema penal, direito e democracia: intercessões ético-discursivas. XVII CONGRESSO NACIONAL DO CONPEDI, 2008. Brasília/DF. Anais do XVII do Congresso Nacional do CONPEDI. Brasília. Disponível em: http://www.conpedi.org.br/manaus/arquivos/anais/brasilia/04_890.pdf. Acesso em 19/07/2015.

Recebido: 22/10/2015

Received: 10/22/2015

Aprovado: 30/01/2016

Approved: 01/30/2016 
